\title{
A Study on the Challenges of Government Primary School Teachers in Dakshina Kannada District
}

\author{
Laveena D’Mello ${ }^{1}$, \& Meena Monteiro ${ }^{2}$ \\ ${ }^{1}$ Assistant Professor, Social Work Department, Srinivas Institute of Management Studies, \\ Mangalore, Karnataka, India. \\ ${ }^{2}$ Associate Professor, MSW Department, School of Social Work, Roshni Nilaya, Mangalore, \\ Karnataka, India \\ E-mail: lavynoronha@gmail.com
}

Type of the Paper: Research Case Study.

Type of Review: Peer Reviewed.

Indexed In: OpenAIRE.

DOI: http://dx.doi.org/10.5281/zenodo.1004676.

Google Scholar Citation: IJCSBE

\section{How to Cite this Paper:}

D’Mello, Laveena., \& Monteiro, Meena. (2017). A Study on the Challenges of Government Primary School Teachers in Dakshina Kannada District. International Journal of Case Studies in Business, IT and Education (IJCSBE), 1(2), 44-51.

DOI: http://dx.doi.org/10.5281/zenodo.1004676.

International Journal of Case Studies in Business, IT and Education (IJCSBE)

A Refereed International Journal of Srinivas University, India.

(C) With Authors.

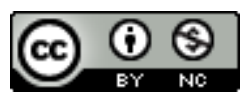

This work is licensed under a Creative Commons Attribution-Non Commercial 4.0 International License subject to proper citation to the publication source of the work.

Disclaimer: The scholarly papers as reviewed and published by the Srinivas Publications (S.P.), India are the views and opinions of their respective authors and are not the views or opinions of the S.P. The S.P. disclaims of any harm or loss caused due to the published content to any party. 


\title{
A Study on the Challenges of Government Primary School Teachers in Dakshina Kannada District
}

\author{
Laveena D’Mello ${ }^{1}$, Meena Monteiro ${ }^{2}$ \\ ${ }^{1}$ Assistant Professor, Social Work Department, Srinivas Institute of Management Studies, \\ Mangalore, Karnataka, India. \\ ${ }^{2}$ Associate Professor, MSW Department, School of Social Work, Roshni Nilaya, Mangalore, \\ Karnataka, India \\ E-mail: lavynoronha@gmail.com
}

\begin{abstract}
Teaching is said to be a noble profession. It is considered to be a profession that identifies the potential in the children and try to bring out the destiny of people. Mother is considered as the first teacher and later teacher in the school will take over the responsibility in molding the children so that they can identify their inner talent and reach their goal in life. Teachers also create the future citizens and to create the administrators, doctors, scientists, engineers and all other professionals. All these are the products of sound teaching order. The Job of teaching is self-rewarding so far as experience, knowledge and emotional satisfaction are concerned. In this profession one may work, earn and remain youthful and young as all the time he/she will be among the youth, thinking new ideas with an innovative spirit. Education is the backbone of the progressing nation which ultimately depends on the teacher. A quality teacher is the one who has a passion for teaching can do tremendous changes in the life of their children. She is also called the torch bearer; he/she moulds the lives of thousands of children. But generally, they are from a low-income group, and with more job dissatisfaction. Financially they are weak, socially they are of low status, and they suffer from stress. In this paper, the researcher tries to highlight various types of stress and the problems faced by the primary level teacher working in the government schools in Dakshina Kannada. 50 teachers were identified randomly for this research.
\end{abstract}

Keywords: Primary teachers, Children, Parents, Administrator, Stress and job satisfaction.

\section{INTRODUCTION :}

Teachers are important to change agents, mentors and academic leaders of the society. The teaching community includes pre-primary, and primary schools teachers, subject teachers, general teachers, physical education teachers, science, commerce, medicine, engineering and technology and language lecturers and readers in colleges and universities. In India, elementary schools provide education from class I to class VIII. The children in these classes are generally aged between 6 to 14 years. It is the next stage after kindergarten (pre-nursery, nursery, prep or lower kindergarten and upper kindergarten). But those who go to government school they go to Anganwadi and Balavadi similar to Kindergarten up to 6 years. The next stage primary education is a lower primary school (class 1st to 3rd) in most school in North India, children in classes 1st to 3rd are taught English, Hindi, Mathematics, Environmental Science, and General knowledge. The next level is a middle school from 4th slandered to an 8th standard where they have the environmental science subject is replaced by general science and Social Studies. However, some school may introduce this concept in class 3itself. Some schools may also introduce third languages in class 5th or even in class 4th. Sanskrit and local state language are the most common third languages taught in Indian schools. At some places, primary education is labeled as the education of class 3rd to class 5th and up to class 2nd as pre-primary education. This is because many new concepts are introduced in this class. Children are taught painting instead of drawing and coloring, exams are taken, and word sum puzzle in math are 
introduced along with geometry. There are three kinds of schools in Karnataka viz. government (run by the government), aided (financial aid is provided by the government) and un-aided private (no financial aid is provided). In the majority of these schools, the medium of instruction is either English or Kannada. The curriculum includes subjects like science, social studies and mathematics apart from language-related subjects. In order to maximize attendance in schools, the Karnataka Government has launched a midday meal scheme in government and aided schools in which free lunch is provided to the students. At the end of the secondary education, the students pursuing the state syllabus have to pass an examination called as SSLC to move on to the next level

\section{SCHOOL CULTURE :}

The success of any educational system depends on good and well-resourced teachers. Teachers cannot be replaced with any other kind of instructional material. Teaching is a profession which needs frequent updating. In this view, teachers should be alert to the new changes happening in the humanity and around the world. Likewise, they need to be continuously abreast with latest theories, research and other addition to the pool of knowledge. It has been observed that teachers who are not competently sound and upgraded are not able to handle the diverse changes and variations in the society, country and the humanity at large. On the contrary female teachers who obtain the latest knowledge and develop their skills can effectively manage the process of teaching and learning. They teach and learn better. Effective teachers require being successful learners as well. Nevertheless, the professional development of female teachers has not been given any appropriate concentration. It is experimental that students graduating from the (government) schools have deprived communication skills and find it hard to contract with problems of life. As student's schools remember the concepts for examination rationale, they are short of investigative, deep and decisive skills like their teachers. Relationship and coordination amongst teachers and with their executive staff are vital for creating an atmosphere of reliance and efficacy. Be short of friendly relations affects the process of effective schooling and learning. The negative effects of politics in schools have extremely exaggerated the cooperative guts amongst teaching the community. In some cases, principals or head teachers give favors to only those teachers who admit their dictations without any hesitation and appraisal. Teachers who question them or ask for more support are deliberately overlooked and ignored. This performance has given birth to suspect and de-motivates some of the teachers who hate smooth talk. Normally school principals run schools like a kingdom, least encourage coordination among the staff, and have lack of vision. In schools there is a culture of backbiting, slurring, tormenting, pleasing and leg pulling among the teaching community, often leads to skirmishes. The final effects of this fall on the students and quality of education. On the whole, due to this the procedure of quality of education in the schools is deeply affected (Khalid, 1998). The situation has increased more pressures on the teachers who become prone to physical discomforts. In this situation, the teachers try to cover the syllabus at the cost of the quality of teaching and learning. Teachers cannot pay individual attention to many students which is a great psychological and social need of students [2].

\section{CHALLENGES OF THE TEACHERS :}

Economic aspect: Owing to getting a smaller amount of financial support, the side of the education system has remained the most underpaid and poor in performance especially in the female. This fact has rendered the education sector as the most unattractive profession in the country. Teachers are less motivated towards and take the least interest in their school duties. Residential facilities: Government does not give any housing lodging to primary school teachers. Teachers posted in farflung areas or outstations where they had to face the problem of lodging and protection. Especially female Teachers cannot have enough money to rent out houses on the money which is given to them and by a hair's breadth make their living. Due to non-availability of executive housing female teachers make extended absentees and are not capable to carry out their duties with complete concentration and happiness. Accommodation is a major irritant in the sound family life of teachers. Due to absence of official accommodation, majority of the time of a teacher is spent in finding an accommodation. It has been observed that when finally a teacher finds an accommodation his next transfer is almost due. Due to which teacher greatly disturbed. It has been experimental that female teachers who are posted in far-off areas are more worried in return transfer to their close stations 
from the time of transfer to the school [3]. This practice depressingly affects the recital of the female teachers which leads to commotion and mental agonies. Frequent transfers: Teachers schools are constantly at the sweet will of education officers and school administration. The transfers are usually made on the basis of favoritism and nepotism. Due to this practice most of the teachers remain in high mental agony, disturbance and pressures. Transfers to remote areas are made to teach a lesson to the teachers who are either disobedient or have affiliation with opposing political party. Sometimes the newly transferred teachers do not find enough time to get adjusted to the new environment. The practice of frequent transfer of teachers creates disturbances for the female teachers and their families. Limited learning resources: The lack of teaching and learning aids in schools creates difficulties in the teaching process especially for female. Some girls' schools even do not have basic aids such as blackboards, attendance registers, offices, libraries, laboratories and upto-date books. Even the majority of girl's schools have lack of classrooms [4].

Supervisions: The process of supervision is filled with bureaucratic underpinnings. In essence, the purpose of supervision is to develop and improve the performance of teachers and students. The supervisors behave like kings and treat the teachers like salves and inferiors. This trend has created mistrust as well as affected the spirit of cooperation among the teachers on one hand and teachers and administration on the other. Coordination and Cooperation: The system of education lacks a mechanism of coordination. This problem has taken rots due to weak communication between the policy makers, staff, parents, and the community. Teachers remain at the receiving end in all areas, e.g., in making of curriculum or any other education policy. Teachers participate only in the implementation, not in the development part.[5] Prevailing Curriculum: Curriculum development is a centralized activity. The curriculum is developed and schools are supposed to implement it without any manipulation. In this regard teachers' role is that of the implementer. They cannot contribute towards the process of curriculum development and evaluation neither they are provided with refresher courses to be in line with the updated syllabi. In many cases, teachers are not aware of the aims or goals of the curriculum for certain levels. This creates gaps between understating of the curriculum and its effective implementation. Textbooks: Textbooks are a very important aspect of teaching and learning process. The development textbook is highly specialized task and teachers are not involved in it. There is lack of training and orientation which reflects in their poor performances. As teachers are expected to cover the syllabus before the examination, by all means, they, in order to overthrow the burden from their head and due to lack of understanding, resort to only reading and preaching the books without taking into account the vital aspects of schooling and learning.

\section{NEED AND IMPORTANCE OF THE PRESENT STUDY :}

It is easily forgotten that teacher is a human being having several social, economic and cultural obligations. If society wants the teacher to perform his/her duties effectively, it is its responsibility to provide them with good service conditions, reasonable financial and non-financial rewards etc. Unless these facilities are provided every allegation made against the teacher will be one-sided and of without any proof of base. Like any other common worker, the teacher is also in a web of several problems, problems relating to salaries, promotion patterns, transfers, working conditions, etc. It is true that the job spirit of working enthusiasm develops only when the workers are paid properly. The salaries paid to teachers are very low and then they cause much dissatisfaction among teachers. A teacher's material possessions are so bad he/she does not get social recognition in this modern world where a semi-educated businessman gets. Simple craftsmen and any other servicemen get recognition and social weight age. In future too teacher will continue to enjoy less social status until his/ her economic status is decided by his / her wealth and income and by the profession he/she does and the contribution he makes for the betterment of people. It is very painful to know that teachers are not so united. They do not have a strong union or association of theirs that which they can fight for rights. As compared to banks or factories teachers association is very weak and if a teacher suffers from any distress no association will come forward to help them. Their exploitation will not stop unless they unite themselves first. Moreover, the policies or promotions that are formed for this profession are of no use. As we observe most of the schools are headed by a person with eight standard and T.C.H qualification and his assistants are graduates and postgraduates. It is good that seniority and 
experience also plays an important role in deciding the school head position, but the government should see to what extent [4].

It is surprisingly true that a teacher joins with the de ignition of an assistant and retires with the same designation. But a simple clerk in a bank or any other government fire can aspire to become an officer of the manager before he retires. It is this fact which stops many of the talented bright individuals by entering into another profession than enter a teaching profession which pays them less. It is not one of the teachings that they do but also teacher perform many other jobs. They are required to shoulder clerical woke like maintaining registers, Preparation of bills, taking height and weight of children and also to run around the government officers to get their work done. Added to this overcrowded and unplanned classes has strongly affected the capacity of a teacher to teach. They cannot give personal attention to each student and because of this fact; many children lag behind as compared to other bright students. This overcrowding makes teachers shout at the top of their voice in order to maintain discipline and also to teach. They need a lot of time for corrections and all this leads to mental strain and their very existence in the profession becomes any agony for them.

Most of the parents feel that once they admit their children to the school their responsibility is over. Parent's initiative in children, education is so largely lacking that teachers find it terribly difficult to bring students to the recommended grade or above average. Here at the best teacher can act as a tutor and guide but not as a spoon feeder. Every lesson and discipline cannot be fed to the child and parents encourage and expect the same from the teachers. It is hard to believe that parents have conveniently forgotten that home is the first school and they are the first teachers. Shortage of teachers is another problem. So when there is insufficient staff others are forced to take up subjects in whom they are not so very competent. Transfers in primary school further aggravate the problems of this profession. The corruption is so high in education department where those who are financially sound pay any amount of bribe and get their transfers done so that they are close to the school, no matter what harm they do to others. Due to this practice, management, students and other staff in the school suffer a lot and result in poor quality of teaching. As reported by Kothari commission, at present there are $40 \%$ schools with single teachers. It is difficult and in a way, we can consider it as a mockery of the whole education system itself, where a single teacher has to manage 4 classes (lower primary) having 150-200 students. He may try his best but however it may be, he cannot do justice for his profession. It is so because he is expected to cover the same syllabus which is also meant for multiple teacher schools. Here he faces the problem of multiple class teaching, heavy workload and adjustment of timetables for four classes. Investigators have found that majority of children who get admitted to government schools are from low socioeconomic groups whose parents are illiterate and are addicts of many evils like alcoholism gambling and so on. So it is natural that their children show less interest in students and also they don't get any encouragement from their parents [5]. Many of them work as coolies and they pay less attention to their children's education. This becomes a problem for teachers and because of those factors naturally, they will not come to the standard of other private schools. As a result teachers in government schools face the problem of inferiority complex and faulty social attitudes; and the government schools are branded as bad school or lowquality schools. Still, the teaching profession is a noble profession. It is people's perception to think that it is chosen by those people who do not have any other alternative.

The secondary education commission was painfully impressed by the fact that the social status, the salaries and the general service conditions of teachers are far from satisfaction Prof. K.G. Saiyidain rightly observes that "teaching is still an unattractive profession which many pesos a last resort". First, the financial prospects offered by the profession are still so far that person with ambition and intelligence is not attracted to it. Secondly, society also does not give this profession the social esteem which it deserves and one of the highest forms of social service. All these aspects have the Impact of stress can be classified into three types, on individual, on family, and on the organization. The impact of Stress on individuals has subjective, cognitive, physiological and health factors to its. The subjective or interpersonal effects of stress are feelings of anxiety, boredom, apathy, nervousness, depression, fatigue, anger, irritability etc. The cognitive effect includes poor concentration, short attention span, and inability to make decisions. The physiological effect can be seen in increased heart and pulse rate, high blood pressure, dryness of throat and excessive sweating. The behavioral consequences are drinking, smoking, impulsive behavior, depression etc. The 
manifest health effects could be stomach disorder, asthma, eczema and other psychosomatic disorder. The impact on the family is distress which is handled by individuals in dysfunctional ways such as reasoning to drinking or withdrawal behaviors will have an adverse effect on their home life. Spouse abuse child abuse, alienation from family members and even divorce could result from dysfunctional coping. The impact on organization effects on the employee is many. The adverse consequences include low performance and productivity, high rates of absenteeism and turnover increased the alienation of the employee from the job etc. It is needless to say that the costs of employee stress to the organization in terms of lost profits declining assets bad image projection poor reputation and loss of future business are enormous $[6,7,8]$.

\section{MAJOR FINDINGS :}

Basic profile: Out of 50 respondents, $10 \%$ of the respondents are male and rests $90 \%$ of them are female. $72 \%$ of the respondent age is less than 30 years of age. These respondents have shown their interest in teaching and earn their living at the early age due to their economic situation in the family. They have also not shown any interest in professional courses and to go for higher education. Majority of the respondents i.e. $72 \%$ are Hindus. The $16 \%$ of the respondents are Muslim and the rest i.e. $12 \%$ are from the Christian background. Hindu's are more due to the Hindu population is more in the region. Majority $76 \%$ of the respondents were from urban areas, $24 \%$ were from rural areas. This is due to many schools are situated in the urban area which gives them more opportunities. $10 \%$ of respondents did their 10th and TCH, 30\% of them did their 12th and TCH and rest $60 \%$ of them did degree and D. Ed. This is because the basic qualification to become the teacher is D. Ed. $68 \%$ of the respondents are married, $12 \%$ of them are unmarried, $12 \%$ of them are separated and $8 \%$ are widow/widower.

Job satisfaction: One of the components of job satisfaction depends upon the number of year's service rendered and the continuation of the job. And the data says, $30 \%$ of the respondents are appointed for less than 5 years, $14 \%$ are between $5-10$ years and rest $56 \%$ of them are above 10 years. Most of the respondents are above 10 years because most of them are working in the same institute for a long time and joined early. They have not done any other job before joining as a teacher. $54 \%$ of the respondents selected this profession due to their interest in teaching, $40 \%$ of the respondents say due to their education they have become a teacher, and rest $6 \%$ did not have any other options so they became teachers. So the majority of them based on their interest became teachers, otherwise, their education will become obsolete.

Relationship and communication: Regarding their relationship in school, with students and with other staff, $54 \%$ of the respondents had a very good relationship with teachers as well as with their staffs, $26 \%$ of the respondents have not so good relationship with their teachers and their staffs, $20 \%$ of the respondents showing poor relationship with their staffs and teachers. When teachers have job satisfaction and love towards their duties definitely develop a good relationship with the staff of their respective school. $84 \%$ of the respondents always show interest in participating in the activities of the school, because they have shown interest in participating in the activities of the school. It is their duty and it is compulsory.

Stress: It is found that $72 \%$ of the respondents have a stress in what they do and rest $28 \%$ does not have any stress. The diagram shows that $52 \%$ of the respondents are irritated when they are doing the job, $20 \%$ of the respondents show anger and they are in any other mood and rest $8 \%$ of the respondents show anxiety while doing the job. This is due to the work pressure and loaded activities which they have to conduct within the speculated period of the academic calendar.

Stress management: There are various reasons that teachers have to undergo pressure while working as a teacher in the school. This may be from various sources by themselves, though collogues, management and sometimes from the neighboring schools also. All this pressure will put them in a stressful situation and they have to overcome it and to manage the stress they have to use various weapons. The data says, $78 \%$ of the respondents use their individual capacity and get encouragement and moral support from their headmistress/res. $90 \%$ of the respondents think that the students' parents cooperate in the school activity and rest $10 \%$ of them thinks that student's parent doesn't cooperate. $66 \%$ of the respondents never had any pressure from colleagues and maintained very good relationship with their colleagues, $32 \%$ are getting sometimes, and $2 \%$ are always getting pressure 
from their colleagues. Not only this, they have to compete with their neighboring schools in many ways. $8 \%$ of the respondents said that they have to compete with other schools often, $36 \%$ of the respondents said only sometimes they have to compete with the neighboring schools and $56 \%$ of the respondents said they need not compete with their neighboring schools. This competition is to get students, giving quality education, conducted internal and external activities, extracurricular and cocurricular activities, reducing school dropouts, getting laurels to the school and getting cent percent results in the examination in their higher standards.

Benefits: The respondents will have various reasons that they get some sort of benefits at their work place like relaxation in timings, leaves, adjustment in the work etc. $90 \%$ of the respondents think that they have benefits of leave and vacations. They get to leave on Saturday afternoon, Sundays, government holidays and regional festival holidays. Only $10 \%$ of the respondents think they will not get CL (casual leave), when it is required. Management will not give willingly.

Teaching Challenges: The challenges for the teachers are when there are slow learners in the class. The regular absentees, unhealthy children, less interested children in the class will be a challenge for the teachers to teach them additionally after the class. And this will irritate them and the data says $40 \%$ of the respondents gets irritated when the child does not respond to their teaching, $30 \%$ of them sometimes get irritated and rest 30\% never get irritated and they have accepted these children and they use different strategies to help them out like making the good students in the class to sit next to the slow learner and to teach them and help them in their studies. 50\% of them get stress and does not like the students who ask them to teach repeatedly, but not in the case of other $50 \%$ teachers.

Health issues: All the teachers will face one or the other health problems. The respondents suffer from different health issues during their teaching profession. $20 \%$ of them suffer from a backache, $60 \%$ of them suffer from a headache, $40 \%$ feel tired and exhausted after their work and feel sleepy after reaching home, $30 \%$ respondents will have leg pain by standing most of the time. And due to these health issues $20 \%$ respondents think that they will not get enough to do their household work.

\section{CONCLUSION :}

Teachers are the building blocks of the student's life. The student's whole life relays on those teaching given by them. If the foundation is good whatever building can be built in the future but if the foundation is not good then it may lead to not such good building, this means the teachers have to build the students well so that they can face any challenges in their upcoming life. To build those students, first of all, that teacher should be mentally as well as physically strong so as to handle any type of students and their parents. Not only will these stress be for the teacher but also the higher authorizes stress will be also on teachers by giving them a target or so. These things should become less so as the teachers teach the student for that student's good future but not to complete their task. The teachers should be respected and understood by the students and their parents.

\section{SUGGESTIONS :}

The respondents have suggested that they need yoga and meditation classes for the students as well as a teacher to give better performances. They need the support and helping hand from the family members in doing household Corus. Management of the school like Headmistress/er should distribute the workload equally to all the teachers so that all will get the opportunity and fewer burdens to the efficient teacher. There is need of school counselor who can help the students as well as teachers and also build a bridge between teacher-student-parents and the management. Less staff and more students will create an imbalance in the teaching. So to avoid this sufficient staff should be appointed. Increase in the pay scale, providing adequate facilities will definitely help them to increase the interest and job satisfaction for the teachers so that they can focus on the commitment to the school. There should not be any difference in the teachers who teach in Kannada medium and English medium schools. Facilities in the schools should be an improved library; laboratory, playground and proper building and infrastructure have to be improved in the schools $[9,10]$. For the better performance delay in payments, sanctioning pension etc should be avoided. Imposing additional duty like polling duty, census duty, too many corrections other works related to pay bills and treasury work should be avoided by providing an adequate number of teachers and peons. These entire activities will de motivate the teachers to continue their profession. Teachers should be 
provided with promotions at the reasonable durations. To improve the attendance and admissions for the school, the authorities should encourage children with scholarships, merit scholarship, loan scholarship etc. and to motivate them to go for higher education.

\section{REFERENCES :}

[1] Chandrashekar C.R. (1999). Stress and Coping the Indian experience. Sage publications, $2^{\text {nd }}$ edition, New Delhi.

[2] Kendall, P. C., \& Kriss, M. R. (1983). Cognitive-behavioral interventions. In: C. E. Walker, ed. The handbook of clinical psychology: theory, research and practice, pp. 770-819. Homewood, IL: Dow Jones-Irwin.

[3] Lyons, L. C., \& Woods, P. J. (1991). The efficacy of rational-emotive therapy: A quantitative review of the outcome research. Clinical Psychology Review, 11(4), 357-369.

[4] Johnson John and Rao V.N. (2002). Human Relations and Organizational Behavior, Deep and Deep publication, Delhi.

[5] Laveena D’Mello, B. M. Govindaraju, Meena Monteiro (2016). A Study on the Challenges Faced by Single Parent on Teenager Care. International Journal of Advanced Trends in Engineering and Technology (IJATET) Impact Factor: 5.665, ISSN (Online): 2456 - 4664, 1 (1), 54-59.

[6] Pestonjee D.M. (2004). Coping with stress, Health Action.

[7] Singh Nirmal (1992). 60 seconds stress Management. Mumbai: Magna publishing Co Ltd., Mumbai.

[8] Lewinsohn, P. M., Steinmetz, J. L., Larson, D. W., \& Franklin, J. (1981). Depression-related cognitions: antecedent or consequence?. Journal of abnormal psychology, 90(3), 213.

[9] Hollon, S. D., \& Beck, A. T. (1994). Cognitive and cognitive-behavioral therapies. In A. E. Bergin \& S.L. Garfield (Eds.), Handbook of psychotherapy and behavior change (pp. 428-466). New York: Wiley.

[10] Rimm, D. C., \& Litvak, S. B. (1969). Self-verbalization and emotional arousal. Journal of Abnormal Psychology, 74(2), 181. 